MÚSICA NAS MOGIS (MIRIM E GUASSU): 1760.

Mogi Mirim - 1760. Antônio da Rocha Campos, mestre de capela em Mogi Guassú, ajusta com festeiros da festa do Divino Espírito Santo para participar da mesma com sua música e comitiva na matriz da povoação; requerera e obtivera das autoridades eclesiásticas competentes que não se permitisse virem músicos de fora para festas dos dois arraiais; transtôrno da ausência do mestre na festa do Divino, celebrada sem música, levou festeiros a deporem contra o mestre ante tribunal eclesiástico local, em autos de justificação.

Os autos (secção de manuscritos restaurados, não inventariados: arquivo da Cúria Metropolitana de São Paulo) são ricos em sugestões sôbre a vida musical na época e elucidam certos problemas pendentes até agora.

Após procurarmos situar o problema no tempo-espaço-contexto, tentamos induzir formas vigentes da

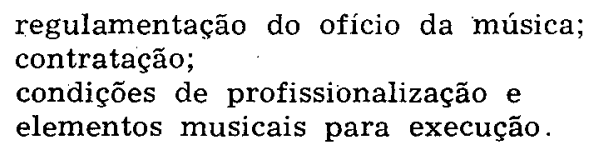

Mogi Mirim $\rightarrow$ 1760. Antiga povoação à margem esquerda do rio do mesmo nome, passou a freguesia em 1751 como território de Jundiaí, da qual dista uns 85 quilômetros para o Norte. Passou à vila em 1769 e à cidade em 1849. Distà uns 155 quilômetros a NNO da capital da antiga província de São Paulo; uns 32 ao $\mathrm{N}$ do rio e localidade de Jaguarí; uns 10 ao $\mathrm{S}$. da antiga povoação de Mogi Guassu, à direita dêsse rio, que freguesia em 1740, foi como tal incorporada ao território de Mogi Mirim em 1769.

São José de Mogi Mirim - 1760. Indice demográfico pequeno, economia de subsistência auto-suficiente, composição social de agricultores pobres, não diferenciada profissionalmente, ou pouco. Mesmo quinze anos depois. quando o nível da expansão econômica é acompanhado" por diferenciação profissional, nesta a música não aparece, apesar da presença de um 
músico ali vivendo (bom músico, conforme o documento que publicamos) .

Mogi Guassu já tivera desde cêdo um mestre de capela, embora não vivendo exclusiva e profissionalmente da música. Garantia com conhecimentos que não podemos estimar as festividades eventuais realizadas nas duas Mogis. Músico amador, vivendo regularmente de suas parcas rendas de roceiro, em 1765 (ano do $1 .^{\circ}$ censo da capital e interior da província) (1), Antônio Euquério de Aguiar é homem de 93 anos. Deve ter desaparecido logo após 1767, ano em cujo censo ainda figura.

Bento de Souza Braga era natural de Mogi Mirim (2); exercera por certo tempo o cargo de mestre de capela em Mogi Guassu. As dificuldades que ali encontrara fizeram-no abandonar a cidade e a profissão ("ofício") não rendosa, antes da quaresma de 1759. Após certo período fora das Mogis retorna para se estabelecer em Mirim em princípios de 1760 ("onde agora já está casado e estabelecido") plantando milho e feijão em seu sítio, onde morava em 1766 com sua mulher, 5 filhos e 2 escravos, sendo "soldado de cavalo".

Em 1776, ano de sua morte, a situação não mudara: sua família e cultura expandem-se, passa a plantar também arroz e amendoim, com 3 escravos e 9 cabeças de gado. A música não lhe dava, nas Mogis, elementares condições profisisonais, apesar de citado como competente para Mestre da capela "em hua cidade, quanto mais nestas freguezias".

Braga exige pagamento por suas músicas: "moradores" de Guassu (festeiros certamente) respondem convidando Euquério, o velho mestre de idade avantajada "com o pretexto de cantar de graça". Rivalidade entre as Mogis "desde que esta freguesia se devedio da de Mogy Guassu" termniam por incompatibilizá-lo com Guassu.

A comunidade habituada com serviços gratuitos de Euquério Aguiar revolta-se e repele Braga que quer profissionalizar-se. Isto nem Rocha Campos conseguiu.

Antônio da Rocha Campos nascera por volta de 1723. Sargento de granadeiros em 1765, com enorme família, dívidas, pou-

(1). - Todos os dados que se seguem foram colhidos nos censos de Mogi Guassu e Mirim, de 1765, 1766, 1767, 1775, 1776, 1777, 1778, 1785, 1797, 1798, 1799 e 1813; Departamento do Arquivo Público do Estado de São Paulo, caixas 114 e 116.

(2). - Sua idade é impossivel de ser calculada: o censo de 1765 lhe atribui 25 anos; o de 1766, 52 anos; o de 1776, 56. Sua espôsa, respectivamente 19, 26 e 30 . 
ca renda e um escravo alugado à dívidas. Alfaiate em 1767, só em 1775 vive da "arte da muzica".

As coisas lhe vão bem: possui umas "moradas de cazas e huâ xacra" (3). Em 1777 e 1778 tem mais um escravo. No censo de 1785 já não figura (abandonara a cidade com tôda a família?). Dessa data em diante não temos mais nenhum mestre de música até o término da fase colonial, apesar da crescente diversificação profissional alcançada na região.

Música para o culto: fonte de solicitação profissional ou para-profissional. Em certas festas anuais mais importantes para a comunidade religiosa local (Patrocínio, Divino, Natal, São Francisco de Borja) instituiam-se festeiros na matriz, responsáveis pela organização da festa religiosa e contratação ou obtenção (no caso de serviços gratuitos) de serviços de músicos.

O Mestre de capela exerce ofício da música sob autorização do vigário da vara eclesiástica. E' um arrematador de serviços musicais, sub-empreendendo serviços prestados por músicos, cantores, ou instrumentistas, trabalhando sob sua orientação e compasso (regência); eventualmente executante de instrumento acompanhante do côro (no caso, a harpa) ou do solista (freqüentemente um tiple=soprano); proprietário dos materiais musicais (papéis de música), adquiridos ou copiados pela sua própria mão; eventualmente compositor de obras executadas na ou especialmente para a ocasião; integrante do côro ou cantor solista conforme a ocasião; não necessàriamente ocupante de cargo estável de música em igreja; sempre teve título identificado com o de regente.

Providências especiais e dificuldades na obtenção de músicos para as festas anuais, estas só realizáveis uma vez ou outra, nas datas mais importantes. A ausência de solicitação devida a pequeno número de festas impede a formação de corporação de músicos no local, criando um círculo vicioso. Mandar buscar músicos fora (por exemplo, Jundiaí a 85 quilômetros) implicava numa série de providências suplementares (condução para um "própio" avisar, e para os músicos, alimentação e um pagamento maior: trata-se de músicos da localidade e daí profissionalização e eficiência maiores) encarecem a realização. Os músicos da localidade (as duas Mogis) não suprem com seu número as necessidades das duas matrizes, realizando fes-

(3). - Dificilmente esta situação económica seria devida. à "arte da música"; Sargento de granadeiros, alfaiate, com familia grande e escravo, desenvolve típica atividade musical semi-profissional de complementação, não ausente em nossos dias e no nosso meio. 
tas concomitantes nas mesma datas. O comportamento dos músicos era para obter proteção especial: recomendação oficial de autoridade eclesiástica competente não permitindo que festeiros tragam músicos de fora, monopolizando (monopólio consistia em não vir músico de fora sem licença do mestre de capela beneficiado ou "sem lhe pagarem o seu compaço") os serviços musicais nas poucas datas festivas. A comunidade só podia dispor de bons elementos (capacidade, eficiência, assiduidade) quando possibilitava pela quantidade de festas, razoável nível de profissionalização e motivação garantindo continuidade da atividade musical .

Ressaltam as atribuições disciplinadoras do tribunal eclesiástico (auditório = vigararia da vara) regulamentando-autorizando o exercício da música nas igrejas locais, aplicando penalidades è suspensão do ofício a eventuais infratores, recomendando a festeiros e ao vigário da paróquia atitudes relativamente à música.

Havia contradição no contexto social relativamente ao problema musical: o que a comunidade podia oferecer - oferece exige do músico, e o que o músico pode oferecer - oferece exige da comunidade. Se o elemento processado, Rocha Campos, fôsse assíduo e o processo inexistisse, continuariam testemunhas e demais implicados a considerá-lo ineficiente ("insuficiente"). Festeiros fundamentados em experiências anteriores procuram resolver a contradição, encomendando músicos de fora. $O$ mestre de capela, continuava monopolizando serviços para garantir continuidade da atividade, fator levando à profissionalização.

Disso tudo destacamos as três figuras:

1. - Antônio Euquério de Aguiar que canta de graça porque pertence a outro contexto ultrapassado.

2. - Bento de Souza Braga, exerce por certo tempo o ofício e o abandona pela agricultura. Sua formação e exigências correspondem a nôvo contexto, mas a comunidade não pode ainda (nem poderá na fase colonial) satisfazê-las. Contradição insolúvel, êle percebe e se retira "só por ivitar contendas em Mogy Guassu".

3. - Antônio da Rocha Campos: soluciona o problema com - pluralismo profissional, forma correspondente às condições específicas do contexto. Tributo pago ao pluralismo: conservação de nível amadorístico proveniente do contexto anterior, e nêle predominante (atividade musical: essencialmente técnica, exige adextramento contínuo). A comunidade percebe (isto he 
notado ainda pelos mais ignorantes que não sabem ler") e o censuram por isso, insurgindo-se contra êle, mesclando criticas artísticas com ética profissional:

"nem sabe solfa de sorte que não esteia erando (sic) ainda os papéis velhiçimos que devia saber de cor".

"...lhe faltão todos os requizitos pa. da. occupaçaô, tanto por naô saber tocar instrom.tos, como por ser pouco perito na arte da solfa comparativ.te aos q. a sabem".

O critério da comunidade, para ser bom mestre da capela, pode ser assim estabelecido: ser como Bento de Souza Braga: exemplo de "suficiência"; ser perito na arte (ou ciência...) da solfa; saber tocar instrumento(s) para "por solfa" (poder compor); saber temperar (afinar) e tocar harpa; ter boa voz e saber cantar; ter um bom côro que não tenha "desmancho" (desencontros); fazer tôdas as vozes: contralto, tenor e baixa (bai$\mathrm{xo})$. Ressalta aqui a especialização dos tiples. Igualmente a escritura e execução de obras a 4 vozes com acompanhamento de harpa, composição esporádica do côro exigindo gastos maiores em solenidades especialíssimas. Do contrário, eram solistas ou duos acompanhados pela harpa, ausente o órgão das igrejas das Mogis. Mas a presença da harpa não exclui a possibilidade de sua função ser de reforçar a parte baixa do órgão; quando a presença do órgão fôr afirmada, a harpa desaparece gradativamente. Pelo menos na região de São Paulo a harpa foi um instrumento comumente usado nas cerimônias religiosas acompanhando o cantor solista, freqüentemente o próprio executante do instrumento. Isto é provado por diversos recibos da primeira metade do século XVIII; ser assíduo; a boa música (bem feita) é elemento de atração para o culto e há os que marchariam léguas para ouvir um bom côro conduzido por um "suficiente" mestre de capela.

"... nâo tinha tantos muzicos quantos podessem assistir a dita festa em hum e outro Arrayal no mesmo dia com capaçidade que naô houvesse rizo": um tiple, uma arpa, o mestre...".

O PROCESSO.

Juizo Ecclesiastico - 1760.

Mogy Mirim Escrivão / Campos (ass.).

(com tinta diversa consta da margem direita no cabeçalho o seguinte: Me.o 2.\%/N.\%/54).

Autos de Justificação do / Emperador do Devino Espristo Santo, a Maro Correia de Sá desta freguezia de Mogy Mirim / Autuação /. 
Anno do Nascimento de Nosso Senhor Jezuz Christo de mil e sete sentos e seçenta annos aos vinte e oito dias do mes de Mayo do dito anno neste Arrayal de Sam. Joze de Mogy Mirim em cazas de morada de mim escrivão ao diante no meado e sendo ahy por parte de Emperador do Devino Esprito Santo a Maro Correa de Sá me foy dada huã sua petiçaõ com o despacho nella posto do Reverendo Padre Vital Gomez Freyre Vigario da. Vara desta comarca requerendome lha tomasse e autuaçe a qual lhe tomey e autuhey sob cargo de meu oficio e he o que ao diante Sessegue que para constar fiz este termo de autuação. Eu Melchior Pereyra de Campos: escrivaõ deste auditorio Ecclesiastico que escrevy.

Dizem Amaro Correa de Sá, eos mais Festeiros da Festa do Divino Esp.to S.to proxima desta Freg.a de S. Jozé de Mogy Mirim, q. p.a bem desua just.a q. requerim.tos q. tem de fazer a S. Ex.ca R.ma lhes he neçess.ro justificar os Itens seguintes.

Que na pres.te Festa do Divino Esp.to S.to ajustou o M.e da Capella com o Cap.m Domingos Nunes Paes,. Pedro Vaz Pires, e o R.do Parocho desta Freg.a, q. não. mandasse vir muzica defora; porq. elle estava pronto. p.a assistir com ella em ambas Freg.as; e por esta Ra-. zaõ suspenderaõ elles Festeiros adeterminaçaõ, q. já tî-. nhãõ em execuçaõ p.a a mandarem vir de outra p.te; ajuntam.te por ter o d.o M.e An.to da Rocha Campos alcançado hum despacho de vm.ce p.a q. o R.do Parocho desta Igreja só admitisse ado Sup.do, e naô outra, sem Lic.a della, o q.l chamado na vespera da referida. Festa naõ quis vir, nem assistir com música.

Item q. requerendo os Festeiros a vm.ce p.a que com pena de suspençaõ viesse cumprir o ajustado foi vm.ce. servido asim mandar; e hindo o Escrivaõ deste Juizo a d.a delig.ca, o rodearaõ em Caza do Sug.do oito ou nove do seu sequito com vozes altas dizendo - viva o povo atemorizando ao d.o official p.a naõ cumprir com sua obrigaçaõ, q. sempre a fes, sem embg.o detudo: como. consta da certidaó, q. junto ofereçe; em regresso, q. o. official the disse. Fran.co de Siq.ra, q. os $\operatorname{Se}(\ldots)$ M.e de Capella (4 palavras ilegiveis) com pancadas.

Item q. não obs.te aintimaçaõ do referido desp.o não. veio assistir com muzica aesta Festa como estava obrig.do mas antes abuzando do devido resp.to, q. deve ter aeste Juizo mandou cantar os muzicos de sua comitiva na Matriz de Mogy Guaçu, assistindo elle no Coro, levantando o Compasso, e cantando com elles, estando sus-penso: o q. he erro de officio.

Item q. alem deste teve outro no dia do Patrocinio de N. Snra; pois naõ quis fazer muzica nesta Matriz de- 
Mogy Mirim, por dever á mesma doze mil, cento e sessenta reis.

Item, q. Ihe faltaõ todos os requizitos p.a d.a occupação, tanto por naõ saber tocar instrom.tos, como por ser pouco perito na arte da solfa comparative aos q. a sabem.

Item q. Bento de Souza Braga tem todos os requizitos p.a hum sufficientissimo M.e da Capella, por ser peritiss.o na arte da solfa, no instromento da arpa, ena execuçaõ de sua boa voz; o q.l (não se) achava neste Continente, o d.o o R.do Vigr.o da (...) informou a $\mathrm{S}$. Ex.ca R.ma a favor do d.o Ant.o (...), dizendo q. este era o mais capáz, (......) naquelle tempo.

P. L. avm.ce seja servido admittir suas test.as na forma, q. requerem cujos dittos com todos os termos nos autos sejaó remettidos ao R.do Vigr.ro G.al ou a $\mathbf{S}$. Ex.ca p.a este defirir com just.a adesobediencia; eq. o Sup.do seja citado p.a vir jurar test.as; e caso o d.o peça v.ta; se lhe de em auto aparte. E. R. M. (ass:) (ao lado: Freire, Como pedem).

Melchior Pereyra de Campos Escrivaó deste auditorio Ecclesiastico do Arrayal de Sam José de Mogy Mirim e Mogy Guaçu e sua comarca certifico e (2 ileg.) que Antonio da Rocha Campos foi sitado em sua propria pessoa por carta que lhe imviey por Antonio Marquez Barboza de cuya mã̃ elle recebeo perante Manoel Ferro Xavier e o Alferez Antonio Joze de Azevedo perante os quais disse o portador o que na dita carta se continha passa o referido na verdade Mogy Mirim 28 de Mayo de 1760 , a de claro que o portador esplicoulhe que era para vir Jurar testemunhas de huns Items; Era Supra. Melchior Pereyra de Campos.

Termo de Asentada.

Aos vinte e oito dias do mes de Mayo de mil e sete sentos e secenta annos neste Arrayal de Sam Jozé de Mogy Mirim, em cazas de morada do Reverendo Padre Vital Gomes Freyre vigario (...) desta comarca onde eu escrivaõ ao diante no meado fui vindo para efeito de Serem inqueridas as testemunhas do Justificante o Emperador do Divino Espirito Santo a Amaro Correa de Sá e sendo ahy por elle foraõ aprezentados e porem chegadas deferindo a todas e a cada huã dellas de perssi - Juramento dos Santos Evangelhos sob cargo do qual prometeraó dizer a verdade do que soubessem e perguntado the foçem e dellas Sam Seus nomes cognomes moradas naturalidades idades e ditos Sam o que ao diante Se Segeu de que para constar fiz este termo de Assentada. Eu Melchior Pereyra de Campos escrivão deste auditorio Ecclesiastico que o escrevi. 
Test.a 1a. / O Ajudante Joze Rodriguez Pimentel natural e baptizado no lugar de nave redonda termo da villa de Castello Rodrigo bispado de Lamego e morador e cazado nesta freguezia de Sam Joze de Mogy Mirim que vive de suas lavouras de idade de quarenta e hum anno pouco mais ou menos testemunha a quem o Reverendo Vigario da vara deferio o Juramento dos Santos Evangelhos em hum livro delles em que poz sua maõ direyta sob cargo do que lhe encarregou jurasse a verdade do que soubesse e perguntado the foce o que elle assim o prometeo fazer $E$ de custume disse nada. Perguntado elle testemunha pelos Items da petiçaó (retro) disse que sabia por (meia linha mutilada) caza de Pedro Vaz Pires (ileg.) mandava vir muzica de fora para (a) Festa do Divino Espirito Santo por se pro (ileg.) (cadir?) aos festeiros que o Mestre Antonio da Rocha Campos naó tinha tantos muzicos quantos podessem assistir a dita festa em hum e outro Arrayal no mesmo dia com capaçidade que naõ houvesse rizo. Sabe mais por ouvir ao Capitam Domingos Nunes Pais e ao Rerevendo Paroco desta freguezia de Mogy Mirim que o dito Mestre da capela juizara com elles naó mandacem vir muzica de fora porque elle tinha tantos que chegacem para a festa de ambas as partes e que para esta de Mogy Mirim a melhor muzica viria: em quanto ao presso sabe por ouvir ao mesmo capitam Domingos Nunes Pais que o dito Mestre da capela dicera que elle se contentaria com qualquer couza que Ihe decem inda que foçe quatro ou sinco patacas porque so queria que naõ viesse muzica de fora: sabe mais que na quarta feira vespera da cençaó escreveo o dito Capitam Domingos Nunes Pais por hum proprio que o imbiou a Jaguari para que se suspendesse a conduçaó dos muzicos de fora a qual diligencia se originou do tal aiuste. Sabe mais que antes de se aiustar couza alguã com o dito Mestre fizera este hua petiçaõ ao Reverendo Vigario da vara requerendo que nenhua outra muzica foce admitida senaõ a sua cujo despacho foi em seu favor. Sabe mais sabado digo que sabado vespera do Espirito Santo de manha Sedo diceraõ alguas pessoas que por voz do dizimeiro viraõ resposta que o dito Mestre ja não viria fazer festa sem se the pagar oito mil reis e ainda para isto havia de se transferir (sic) dita festa para outro dia. Do que bem (ileg.) que se the tinha mandado (......) (ileg.) juizo (ileg.) para que viesse o dito Mestre (meia linha ileg.) disse que sabia por vir (ileg.) e despacho que o Emperador e demais festeiros requeriaõ ao Reverendo Vigario da vara que comppelisse ao dito Mestre com penna de suspensaõ viesse comprir o ajustado e que aquele assim o mandara. Disse mais que sabe por ouvir da 
voca do Escrivaó que indo este notificar ao Mestre da Capela a Mogy Guassu la o rodiaraó em sua caza huns apaxonados dizendo em vozes altas: viva o povo: entre os quais estavaõ algums armados e hum delles era Francisco Xavier como mais a valentado; e que soubera na canoa que lhe queriaó espancar. Ao terceiro Item disse que sabe de certo por prezenciar que o dito Mestre da capela naõ veio assistir com muzica aesta festa naõ obstante mandarse-lhe cavalo e a notificaçõa, que o obrigavaõ a vir: ouvio mais que Manoel dos Santos Meirinho deste Juizo, e o Capitam Joze de Souza morador de Jundiahy diceraõ que o dito Mestre da Capela assistira com seus muzicos no coro cantando com elles depois de estar suspenso e na verdade os muzicos haviaõ de ser nessesriamente os de sua comitiva. Ao quarto Item disse que o dito Mestre da capela naõ quiz vir fazer muzica nesta Matriz de Mogy Mirim no dia proximo passado do $\mathrm{Pa}-$ trocinio de Nossa Senhora porque elle testemunha tinha feito imbargo em oito patacas que a fabrica desta Igreja lhe devia dar ao dito Mestre da cantoria do dia de Sáo Francisco de Borja para recebersse a conta do que elle era devedor a esta Igreja cujo Procurador se lhe testemunha. E por cauza desse outro erro de oficio elle esteve esperando athe meyo dia, (rezou-lhe?) somente a missa. Ao quinto disse que na (meia linha mutilada e ileg.) só Mestre nos (meia linha ileg.) porque elle mesmo testemunha ficando por seu fiador, isto por fiado, Ao dito (Mestre?) este tem uzado de maus termos a sete annos pouco mais ou menos. Deste modo queixamse varios. Ao sexto disse que o que neste Item Se contem, he publico e notorio; porque nas suas muzicas numca vio ao dito Mestre tocar e alem disso o seu coro sempre tem desmancho e mais provoca rizo que a devoçaó; e que na festa de São Francisco de Borya tinha a arpa de seu coro dois burdois de linha de pescar de que todos fizeraõ mofa; e quando o instromento estava tambem imcordoado, tambem naõ podiaó deixar de ficar, como ficaraõ, emcordoados os muzicos nessa funçaõ: o que naõ tem sucedido somente nessa muzica delle. Ao setimo disse que Bento de Souza Braga tem muita suficiencia para ser Mestre da capela em hua cidade, quanto mais nestas freguezias; porque logo immenda os erros dos outros muzicos, cantando na voz do que erra athe esse tornar a sertar, e tornando outra vez a sua. E' pereticisso (peritissimo?) na arte, e faz todas as vozes pois a tem boa. E se Antonio da Rocha Campos teve em seu favor em formaçaõ a seu digo imformaçaõ do Reverendo Vigario da Vara, foi porque Bento de Souza Braga tinha deixado de Mestre da Capela disgostoso pelas de- 
satensoins que lhe tinhaõ feito em Mogy Guassu, naõ obedecendo aos despachos que o dito aprezentava do mesmo Reverendo Vigario da Vara a quem cumprir e se achava fora deste conthinente em cuia falta era Antonio da Rocha Campos o mais capaz ainda que contada a sua insuficiencia por naõ haver para onde se rricorer e talvez naõ advinhando que elle. deixasse eantas festas sem muzica. $\mathbf{E}$ mais naõ disse asentando com o Reverendo vigario da vara. Eu Melchior Pereyra de Campos escrivaõ deste auditorio Ecclesiastico que Escrevi. Joze Rosa Pimentel (assinado) Test.a 2a. / O Capitam Domingos Nunez Pais natural e baptizado na freguezia de nossa Senhora da Conceiçaõ dos Guarulhos deste bispado de Saõ Paulo morador nesta de Mogy Mirim e nella cazado que vive de suas lavouras de idade de sincoenta e dous annos pouco mais ou menos testemunha a quem o Reverendo vigario da vara deferio o juramento dos Santos... (etc). Perguntado elle testemunha pelos Items da petiçaó retro disse que o Mestre da capela Antonio da Rocha Campos pedira a elle testemunha foce em seu favor alcançando dos festeiros da festa do Divino Espirito Santo; que naõ mandaçem vir muzica de fora porque elle mestre viria cantar com hum tiple, e com Bento de Souza. Braga deste Arrayal ainda que por sua propria pessoa lhe dessem quatro ou sinco patacas: pois elle aseitaria tudo, e era escuzado mandar vir muzicos de fora tendo-os elle para suprir a festa desta freguezia e a de Mogy. Guassu. Pela qual razão elle testemunha mandou um propio a Jagoary para suspender-se a ordem, que se tinha dado para a conduçaó dos muzicos de fora e na mesma ocaziaó vio elle testemunha hum despacho do Reverendo vigario da vara em (que) mandava que o Reverendo Paroco (de Mo) gy Mirim não admitisse outra muzica (...) licença do Mestre da capela por reque(rimento) que este the tinha feito queixandose (de) - mandarem os festeiros vir outra havendo-(se) na terra: Sendo porem chamado no Sabado de manhan, vespera do Espirito Santo, por hua carta escreveo que viria se lhe mandassem cavalo; mandouselho e naó veio nem tiple, como tinha ajustado: fazendo com que os portadores tomassem tantas vezes o caminho de Mogy Guassu e pasaçem o rio. Ao segundo disse que fizeraõ o Imperador e mais festeiros petiçaõ ao Reverendo vigario da vara e este mandou que o dito Mestre da Capela foce notificado com pena de Suspençaõ de seu oficio, que puzese a muzica que tinha ficado por no dia seguinte da festa: foi noteficado pelo Escrivaó deste Juizo; e se he Serto o que o dito Escrivaó afirmou, quazi Se levantaraõ com elle; porque rodeamno oito ou nove 
pessoas e alguas armadas, entre os quais conheceo a Francisco Xavier amigo do dito Mestre, e entre todos se levantou hum motim que dizia viva o povo: o que sertamente merecia castigo. Alem disto coreo fama depois, o intento deles lavantados era espancar ao tal official da diligencia. Ao terceiro disse que o dito Mestre da capela nada comprio do que prometeo porque naó veio assistir a festa deste Arrayal nem mandou muzico algum, indo-lhe cavalo: mas antes fazendo, ou mostrando fazer pouco cauzo da suspençaõ que lhe foi inthimada naõ so mandou cantar na festa de Mogy Guassú os muzicus de sua comitiva o que he Sertissimo, mas tambem, segundo dizem; assistio no coro cantando e levantando compasso: o que melhor diraõ os que asistiraõ na dita festa. Ao quarto disse que no dia do Patrocinio de nossa Senhora do anno passado ouve neste Arrayal missa somente rezada e naõ cantada ja ao meyo dia por naõ aparezer, nem mandar dito Mestre da capela sua muzica; (1 palavra mutilada) para que se naõ descontasse o que elle devia ( 1 mut.) Igreja como entaõ o afirmou perante (todos o) procurador della e o Reverendo Vigario. Ao quinto disse que he publico e certo que o tal Antonio da Rocha Campos he custumadu naõ uzar lizura e verdade nos seus ajustes pois todos disto se queixaõ, especialmente o Capitaó Joze de Souza e Siqueira. Ao Sexto disse que o. Mestre Antonio da Rocha Campos naõ sabe tocar instromentos, nem sabe solfa de sorte que naô esteia actual mente erando ainda os papeis velhiçimos que devia saber de cor; $e$ isto he notado ainda pelos mais ignorantes que naó sabem ler. Em quanto a arpa, he tam certo que a naó sabe, que nem temperar comunga. Ao setimo disse que Bento de Souza Braga he sem duvida mui perito no estromento da arpa, boa vos, e execuçaõ de qual quer papel: o qual deixou de ser Mestre da capela so por ivitar contendas em Mogy Guassu, onde he pouco a Seito de algums moradores della tanto por elle. lhe pedir o que the deviona de suas muzicas, como por cerem adverssarios aos de Mogy Mirim desde que esta freguezia Se devedio da de Mogy Guassu. E se Antonio da Rocha Campos teve em seu favor emformaçaõ do Reverendo Vigario da Vara, pela qual constava ser elle o mais capas que nesta terra asistia foi porque ja Bento de Souza Braga nesse tempo tinnhasse auzentado com animo de naõ tornar para estes dous Mogis, onde agora ja esta cazado e estavalecido: $\mathrm{E}$ mais naõ disse e assinou com o Reverendo Vigario da Vara. Eu Melchior Pereyra de Campos escrivaó deste auditorio Ecclesiastico que o escrevi (seguem as assinaturas de Freyre e Domingos Nunes Pais). 
Tes.ta 3a. / Bento Correa Garcia natural e baptizado (na fregue)zia de nossa Senhora Santa Anna da Villa. (de Par)naiba deste bispado de Sam Paulo e morador na freguezia de Nossa Senhora da Conceiçaõ de Mogy Guassu homem solteiro que vive de seus negocios, de idade que disse ser de trinta e tres annos pouco mais. ou menos testemunha a quem o Reverendo... (etc. idem testemunhas anteriores).

E perguntado elle testemunha pelos Items da petiçaõ retro disse. Ao primeiro que sabia de certo que fazendo o Mestre da capela Antonio da Rocha Campos hua petiçaõ ao Reverendo Vigario da vara desta comarca em que lhe requeria mandasse ao Reverendo vigario da Igreja de Mogy Mirim naõ conssentiçe muzica de fora. na festa do Divino Espirito Santo, despachara este em favor do Mestre da capela. Ao segundo disse que sabia tambem de certo que o dito Mestre da capela fora noteficado as sete horas da note na vespera do Espirito Santo para comprir o aJustado com os festeiros isto he para trazer muzica para a dita festa sob-pena de Suspençaó; e que nesta ocaziaó estavaõ dous homens para o desauturizalo com pancadas, os quais eraõ Joze Pereira Coutinho de caza da tia do dito Mestre da capela e Francisco Xavier Chaves, que andavaõ bebados; ( 1 ileg.) intento mau exzecutariaõ junto a porta delle testemunha a naô ser o dito Mestre, que os dessuadio o que tudo elle testemunha prezenciou. Ao terceiro disse que sabe por prezenciar que o dito Mestre cantou na festa do Divino Espirito Santo asistindo a seus muzicos no coro, e levantando compasso e isto depois da intimaçaõ da Suspençaõ: porque (a) intimaçaõ foi feita as sete horas da. noite anteçedente, e a muzica (ao m)eyo dia; e que o mesmo Reverendo vigario de Mogy Guassu, lhe admetira. Ao quarto disse que sabia que o dito Mestre na veyo fazer muzica na Matriz de Mogy Mirim no dia do patrocinio de Nossa Senhora o anno proximo passado. Disse mais, o Mestre da capela, naquele tempo lhe dicera que o procurador de Mogy Mirim querialhe fazer embargo na paga da muzica para apilicar, a satisfaçaó do que o dito Mestre deve a mesma Igreja. Ao quinto disse que o dito Mestre uza nos seus tratos pouca lizura, e menos verdade. Ao Sexto disse que o dito Mestre naô. sabe temperar arpa, nem lhe consta que saiba instromento algum para por solfa, e varias vezes no coro comete seus erros que todos os preçevem: Ao setimo disse que he certo tudo o que se dis neste artigo acerca da boa vos de Bento de Souza Braga, da Sua pericia na solfa, e no instromento da arpa, e a cerca de ter o Bento digo o mesmo Braga deixado a mestrage da capela, quan- 
do o Reverendo Vigario da vara emformou a favor de Antonio da Rocha Campos. $\mathbf{E}$ mais naõ disse e se assinou com o Reverendo vigario da vara. E eu Melchior (etc. etc.) (segue a assinatura de Freyre e Bento Corr.a. Garcia) .

Test.a 4a. / Bras Esteves do Prado natural e baptizado na freguezia e villa de Nossa Senhora da Conceiçaõ de Jacarahy deste bispado de Sam Paulo e morador nesta de Sam Joze de Mogy Mirim e nella cazado que vive de suas lavouras de idade de secenta annos pouco mais ou menos, testemunha a quem o Reverendo (etc. etc.).

$\mathrm{E}$ perguntado elle testemunha pelos Items da petiçaõ retro disse que ouvira dizer que o Mestre da capela Antonio da Rocha Campos fizera petiçaõ para naô se admitir muzica de fora porque elle estava pronto para asistir com ella em hua e outra freguezia, e a o Capitam Domingos Nunes Pais ouvio tres ou quatro dias antes: da festa, que o Mestre da capela a Justara com elle vir fazer a muzica e que lhe diçera que tudo aSeitaria inda que lhe dessem quatro ou sinco patacas somente pela sua acistencia de sua pessoa; e que isto the diçera o dito capitam admirandoçe de que eu contar que o dito Mestre me dicera no Domingo anteçedente que naó vinha cantar nessa festa de Mogy Mirim, menos que naõ lhe dessem hua dobla: porque se havia dinheiro para os fora, (sic) aquem naô havia de dar menos disso, tambem devia avelo para os da terra. Ao segundo disse que sabia por ouvir que o dito Mestre fora noteficado com pena de Suspençaõ para vir comprir o seu a Juste: tambem ouvio dizer em duas parte que la queriaõ espancar ao escrivaõ na funçaố da noteficaçaô. Ao terceiro disse que ouvio dizer atodos os que vieraô de Mogy Guassu, que o dito Mestre la cantara com os seus muzicos, naõ obstante a intemaçaõ da Suspençaõ, e Julga elle testemunha que se cantou foi tambem por fazer pouco cauzo: porque em outro despacho mandando que se pagasse o compasso ao que entaó servia de Mestre da capela, e sendo apresentado pelo natal, naó fizeraó cazo, nem estiveraõ por (1 ileg.) dizendo que Se o que entaõ era Mestre da capela teimasse hir no coro haviaõ de lançalo delle (aba)ixo; e andavaó todos quazi amutinados, dizendo viva o povo. Ao quarto disse que o dito Mestre da capela naó ve()i(o) fazer muzicos muzica (sic) no dia do patrocinio de Nossa Senhora na Matriz de Mogy Mirim: o que he certicimo porque elle testemunha o prezençiou: e ouvira dizer, que numca houvera de vir ca so por lhe naó embargarem a paga da muzica para se dar a Igreja a quem o dito Mestre he devedor de certa 
quantia. Ao quinto disse que o dito Mestre nos seus contratos e aJustes quazi toda viagem custuma faltar. Ao Sexto disse que o dito Mestre [he volgarmente sabido] naõ tem capacidade para ser Mestre da capela, se naó onde absulutamente naõ houver outro que intenda; porque os seus, eros saõ continuados, e porcetiveis de todos. Ao setimo disse que Bento de Souza Braga nõa so he capas para Ser Mestre da capela em Mogy Mirim, Se naõ em hua cidade; e isto o dizem os pacageiros que o conheçem. Disse mais que Se Antonio da Rocha Campos teve algua imformaçaõ a seu favor, em que se afirmaçe que era o mais capas dos muzicos que se achavãa na terra, foy porque nesse tempo Bento de Souza Braga ja estava fora della com animo de naõ voltar por disgostos que tinha tido com os moradores de Mogy Guassu, os quais sem atender a que elle era o Mestre naquelle tempo, entreduziraõ ao Mestre velho Antonio Euquerio de Aguiar com. o pretexto de canta (sic) de graça. E mais naõ disse e assinou com o Reverendo vigario da vara. E eu Melchior (etc. etc.) (segue assinatura de Freyre e Bras Esteves do Prado).

Test.a 5a. / Jeronimo Alvarez de Araujo natural e batizado na freguezia de Nossa. Senhora da Luz dos Pinhais de Curitiba desse bispado de Sam Paulo homem solteiro e morador nesta freguezia de Sam Joze de Mogy Mirim e nella Dizimeiro de idade que disse ser de trinta e sinco annos pouco mais ou menos testemunha a quem - Reverendo (etc. etc.).

$\mathrm{E}$ perguntado elle testemunha pelos Items da petição retro disse que no Sabado de manhã vespera do Espirito Santo entregara ao Mestre da capela Antonio da Rocha Campos, que o capitam Andre Correa de Lacerda. lhe tinha dada para entregar em mão propria, e logo que chegasse ao dito Mestre; e que tambem troxera a resposta do dito Mestre que vocalmente lhe disse estas palavras eu la naõ vou menos que me naõ dem oito mil reis por minha pessoa e tipli; e ainda andeme mandar cavalos: outra muzica naó pode cantar sem minha licensa. Isto mesmo que tinha elle testemunha ouvido de voca expoz ao Capitam Domingos Nunes Pais, o qual tornoulhe estas palavras seguintes: pois isso naõ he o que elle a Justou com migo. Sabe mais por ouvir dizer que os festeiros lhe tinhaõ mandado cavalo; e elle naõ viera. Mais: que ja antecedente mente tinha ouvido dizer varias pessoas que o dito Mestre tinha vindo em pessoa (2 ilegiv.), dias antes da Sençaõ, (2 ileg.) por pitiçaõ Seu requerimento ao Reverendo vigario da vara pedindolhe naõ concentiçe como vigario da Igreja que algum cantaçe na festa do. Espirito Santo proxima cem Sua li- 
cença por que tinha muzicos para ambas as freguezias; e elle testemunha julga que elle obteria: porque o dito Mestre lhe disse que so viria no cazo que lhe decem oito mil reis: do qual dito se colige que podia Se elle quizeçe. Ao segundo disse que sabia por ouvir dizer aos moradores de Mogy Guassu, que o escrivaó deste Juizo Melchior Pereyra de Campos noteficara ao dito Mestre a requerimento dos festeiros para que vieçe cantar no outro dia com pena de Suspençaõ; e que o dito Mestre, naó obstante a intimaçaõ do dito despacho do Reverendo Vigario da Vara que the foi feita ainda a tempo, porque se lha fez de noite [levava ordem para noteficalo ainda que de noite foçe.], naõ quis vir. No mesmo Arrayal de Mogy Guassu lhe diceraô varios moradores que na ocaziaõ da notificaçaõ houve hum alvoroço, em que quizeraõ espancar ao mesmo escrivaõ e de hua roda se ouvio -- viva o povo - Ao terceiro disse, naõ por prezenciar, mas por ouvir aos mesmos moradores de Mogy Guassu, que o dito Mestre da capela cantara no coro com os muzicos de sua comitiva custumados na festa que Se fez em Mogy Guassu depois da intimaçaõ da Suspençaõ. Ao quarto disse nađa. Ao quinto disse que naõ sabe o que o tal Mestre uza nos seus tratos com outras pessoas: mas que com elle testemunha nenhuma verdade uza. Ao Sexto disse que o tal Mestre naó he capas do imprego que ocupa; por que elle testemunha tem prezenciado (sic) varias vezes haver erros no seu coro de sorte que cauza rizo aos circonstantes na Igreja de Mogy Guassu; e desta incapacidade nimguem o pode duvidar, pois o Sabem todos. Ao setimo disse que Bento de Souza Braga he muito perito tanto no instromento darpa como na ciençia da Solfa; e na sua vos tem a especialidade de fazer della o que quer ja cantando baixa, ja tenor, ja contralto. Em quanto ao mais que se diz no dito artigo naõ sabe, se naõ que este Braga fora para fora o anno passado antes da quaresma com animo de naõ voltar, mais. $\mathbf{E}$ al naõ disse e assinou com o Reverendo (etc. etc.) (segue assin. Freyre e Heronimo $\mathrm{Alz}$ de Araujo).

Test.a 6a. // O Capitam Manoel Luiz Gomes natural e baptizado na freguezia de Santa Maria de Goyos termo de Barcelos Arrcebispado de Braga e morador na freguezia de Nossa Senhora da Conceiçaõ de Mogy Mirim digo Guassu e nella cazado que vive de suas lavouras de idade de secenta e sete annos pouco mais ou menos testemunha a quem o Reverendo (etc. etc.).

E perguntado elle testemunha pelos Items da petiçaó disse que ouvira dizer (1. ileg.) em Mogy Guassu que o Mestre de Sua capela Antonio da Rocha Campos fizera hua petiçaó ao Reverendo vigario da vara reque- 
rendolhe que como vigario da Igreja naõ admitece muzicos de fora porque tinha noticia que os festeiros do Devino Espirito Santo de Mogy Mirim tinhañ mandado buscar de fora, tendo elle Mestre da capela muzicos suficientes na terra para hua e outra freguezia. E que esta petiçaó fora feita antes do dia da cençaó. Ao segunrlo disse que ouvira dizer que o escrivaó deste Juizo noteficara ao mesmo Mestre da capela para que com pena de Suspençaõ vieçe fazer muzica, comforme tinha aJustado, no dia seguinte; e que esta noteficaçaõ fora feita as sete oras da noite no sabbado vespera da dita festa. Ouvio mais por lhe dizerem que na tonçã̃ de tal noteficaçaô ouvera um alvoroço e que dous homens quizeraõ espancar ao official da diligencia. Ao terceiro disse que naõ obstante a intimaçaõ da Suspençaõ, o dito Mestre naõ veio asistir a dita festa naõ veyo digo a festa nesta freguezia de Mogy Mirim com muzica: porque todos os seus muzicos e elle se achavaó no dia do esprito Santo cantando no coro da Matriz de Mogy Guassu, o que elle testemunha prezenciou. Ao quarto disse nada. Ao quinto disse nada. Ao Sexto disse que o dito Mestre da capela pelo que ouve aos mais; que elle testemunha naõ pode afirmar couza algua neste particolar por naõ intender da Solfa. Ao Setimo disse que Bento de Souza Braga tem muito mayor capacidade para a tal ocupaçaõ que Antonio da Rocha Campos. E esta afirma elle testemunha náó porque todos em Jeral o reconhecem mas pelo que elle testemunha prezenciou. E mais naõ disse e se assinou com o Reverendo (etc. etc.) (segue ass. Freyre e Manoel Luiz Gomes).

Test.a 7a. // Mauricio Joze Machado natural e baptizado na freguezia de Santa Anna do Patriarcado de Lisboa e morador nesta freguezia de Mogy Mirim e nella cazado que vive de seu negocio de idade de sincoenta annos pouco mais ou menos testemunha a quem o Reverendo (etc. etc.).

E perguntado elle testemunha pelos Items da petiçaõ retro disse que na vespera da Ascençaõ do Senhor na terça Feira estando elle testemunha na sua porta lhe mostrou o Mestre da capela Antonio da Rocha Campos hum despacho do Reverendo Vigario da vara em que mandava que naõ se admitisse outra muzica sem licença do dito Mestre ou sem lhe pagarem o seu compaço; e depois de lho mostrar acrecentou que mais querem os festeiros de Mogy Mirim? Naó vasta que venha cantar Bento de Souza com migo e hum tiple? E respondendo elle testemunha que vastava, tornoulhe o dito Mestre: pois esperem me aqui, que eu ca estou sem falta sabbado anoite vespera do Esprito Santo; e foi de- 
sacerto terem o travalho de mandar conduzir muzicos de Jundiahy tenoos eu para ambas as freguezias na terra. Por sinal que depois da despedida do dito Mestre advertio a Mulher delle testemunha que ouveçe de perparar a cea naquelle Sabbado: pois bem tinha ouvido o Mestre da capela, que havia de vir. Disse mais que sabe por prezenciar que logo se expedio proprio a Jaguary, para dahy se mandar outro proprio a suspender a ordem que se tinha dado para a conduçaó dos muzicos de fora. Ao segundo disse que sabe por prezençiar que no Sabado de manhã vespera do Espirito Santo Se escreveo ao dito Mestre, avizando o para que vieçe no mesmo dia com o seu tiple, como tinha aJustado: naõ sabe porem qual foi a reposta que trouxe o portador. Sabe mais que os festeiros pediraõ hum cavalo Ao Alferes Joze Gomes de Gouvea, e lho mandaraõ para Sua conduçaõ; e por estar ocupado naõ sabe o que se pacou: mas esta certo que incontrou com o Escrivaõ deste Juizo, o qual de a cavalo the disse que hia noteficar com pena de suspençaõ ao Mestre da capela para que no dia seguinte se achaçe a oras com muzica pronta, como tinha aJustado. Naõ no outro dia da festa, mas nas oytavas do Espirito Santo ouvio dizer que em Mogy Guas-. su queriaõ aquentar o corpo ao official da diligença; e he custume nestas terras desauturizar com pancadas ou com mortes aos officiais de Justiça tanto secular, como Eccleziastica. Ao terceiro disse que naó prezenciou mas lho afirmaraó pessoas didedignas que o dito Mestre naõ obstante a Suspençaõ, que lhe fora intimada no Sabbado a noite na vespora cantou no dia da festa aSistindo a seus muzicos levantando compaço no coro da Matriz de Mogy Guassu. O que sabe por prezenciar he que naõ veyo nem mandou muzica a Mogy Mirim dando por desculpa que naõ tinha muzica para ambas as partes; e que se quizecem muzica transfericem a festa para outro dia. Esta ultima clausula (mutilada) naõ ( 3 palavras mutiladas). Ao quarto disse que sabe por prezenciar que o mesmo Mestre da capela naõ quiz vir fazer muzica no dia do patrocinio de nossa Senhora o (an) no proximo passado por dever a esta Igreja de Mogy Mirim certa quantia de dinheiro, e querer o procurador embargar a paga da muzica, visto que de outra sorte a naõ pode aver. Ao quinto disse que todos em Jeral tem ao dito Antonio da Rocha Campos por homem de pouca firmeza na sua palavra. Ao Sexto disse que por elle testemunha naõ saber Solfa naõ pode afirmar se o tal Antonio da Rocha Campos he, ou naõ capas para Mestre da capela: mas que por ouvilo naõ dara hum passo: pelo contrario para ouvir a Bento de Souza Bra- 
ga, caminhara inda huã Legoa; e assim respondeo ao ultimo Item. Mais naõ disse e Se assinou com o Reverendo vigario da vara. $\mathbf{E}$ eu Melchior (etc. etc.) (segue ass. Freyre e Mauricio Joze Machado).

Termo de concluzaõ // Aos trinta e hum dias do mes'de Mayo de mil e sete sentos e secenta annos neste Arrayal de Sam Joze de Mogy Mirim em cazas de morada de mim escrivaó ao diante no meado e sendo ahy fiz estes autos concluzos ao Muito Reverendo Senhor. Doutor Vigario Geral da cidade de Sam Paulo Manoel Joze Vaz para nelles deferir o que the pareçer Justiça de que fiz este termo. Eu Melchior Pereyra de Campos escrivaõ deste auditorio Ecclesiastico que o escrevi.

Termo de remessa // Aos trinta e hum dias do mes de Mayo de mil sete sentos e secenta annos neste Arrayal de Saõ Joze de Mogy Mirim em cazas de morada de mim escrivaõ ao diante no meado e ahy em comprimento da petiçaó Supra remety estes autos para o Juiz Suprior da Cidade de Saó Paulo declaro que estes (autos?) constam de 12 meyas folhas de papel as quais vaõ rubricadas com a minha rubrica que he Campos de que fiz este termo de Remessa Eu Melchior Pereyra de Campos escrivaō deste auditorio Ecclesiastico que o escrevi. // clos.

\section{RÉGIS DUPRAT}

Licenciado em História pela Faculdade de Filosofia, Ciências e Letras da Universidade de São Paulo. 